\title{
First case of COVID 19 associated with CML at time of presentation
}

\author{
Khaldun Obeidat ${ }^{1}$, mohamed yassin ${ }^{2}$, and mohamed aboukamar ${ }^{2}$ \\ ${ }^{1}$ Hamad Medical Corporation Department of Medical Education \\ ${ }^{2}$ Hamad Medical Corporation
}

May 21, 2020

\begin{abstract} SARS-CoV-2 and work up for Leukocytosis confirmed the diagnosis of CML.

First case of COVID 19 associated with CML at time of presentation

Khaldun obeidat ${ }^{1}$, Mohamed aboukamar, ${ }^{2}$ Mohamed A Yassin $^{3}$

1. Department of medical education HMC

2. Department of infectious diseases, HMC

3. Department of medical oncology NCCCR, HMC
\end{abstract}

COVID-19 outbreak has been a serious threat and it has been reported with different presentations and complications, here we report a 39 year old healthy male who presented with respiratory symptoms and investigation revealed that he is positive for

\section{Corresponding author}

Dr. Khaldun Obeidat

Department of medical education HMC

Dr.khaldun.obeidat@gmail.com

Keywords:

COVID 19, SARS-CoV-2, CML, first prostration

\section{Key clinical massage:}

We report a 39 year old male, who was diagnosed with COVID19 with CML at time of presentation, although this association could be a coincidence, we report this case to increase awareness of such association between COVID19 and other neoplasms.

\section{Introduction:}

Coronavirus disease 2019 (COVID-19) is an infectious disease caused by severe acute respiratory syndrome coronavirus 2 (SARS-CoV-2)[1], The disease was first described in December 2019, after a series of unexplained pneumonia cases were reported in Wuhan, Hubei Province, China in December 2019.Full-genome sequencing and analysis indicated that the coronavirus that causes COVID-19 is a betacoronavirus in the same subgenus as the severe acute respiratory syndrome (SARS) virus as well as several bat coronaviruses[2].

Since the beginning of this disease it was spreading rapidly and by the end of April 2020 it was affecting 210 countries around the world as per WHO with total number of cases Exceeded 3 million with more than 
200 thousands deaths [3], Most of the cases presented with symptoms like fever, cough, general fatigue an myalgia, however some case presented with symptoms related to the gastrointestinal system such as nausea, vomiting and diarrhea. Previously reported cases of CML described patients with CML in different phases infected with COVID 19 however our case is unique since he presented with respiratory symptoms and work up of leukocytosis revealed CML, up to our knowledge this the first case of CML presenting with COVID 19 infection as initial presentation.

\section{The case:}

This is a 39-year-old male with no previous medical issues presented with 2 days history of fever and dry cough which was associated with shortness of breath, review of systems was unremarkable other than what mentioned above. On physical exam the patient was in respiratory distress, febrile with temperature of 38.5 $\mathrm{C}$, and he was requiring 2 liters of oxygen via nasal cannula to maintain oxygen saturation above $94 \%$, Heart rate was 110 and blood pressure was $120 / 75$, chest auscultation was positive for bilateral crackles, abdominal exam was unremarkable with no palpable organs.

Initial investigation showed high white blood cells with count of $68.8^{*} 10^{\wedge} 3\left(4-10^{*} 10^{\wedge} 3\right)$, Hemoglobilin level was $10.9 \mathrm{gm} / \mathrm{dl}$, MCV 84.8 and platelets count of $629^{*} 10^{\wedge} 3$ with normal liver and kidney function, and the patient tested positive for COVID 19, XR chest showed right upper and left lower lung zones of infiltrates and the patient was admitted as case of COVID 19 pneumonia, further evaluation including peripheral smear showed normochromic normocytic anemia. Severe leukocytosis, Slight anis-poikilocytosis, with occasional NRBCs, Leukocytes shift to the left with few circulating blasts, Slight increased platelets and the picture is consistent with CML, Ultrasound abdomen showed Hepatosplenomegaly with liver size of $22.2 \mathrm{~cm}$ and spleen of $17.7 \mathrm{~cm}, \mathrm{BCR} / \mathrm{APL}$ testing from peripheral blood sample was consistent with a rearrangement of BCR/ABL1 in $96.5 \%$ of nuclei so the patient was diagnosed with chronic myeloid leukemia.

During hospitalization the patient was stared on COVID 19 treatment as per our hospital protocol so he was started on azithromycin, hydroxychloroquine, ceftriaxone, oseltamivir and lopinavir/ritonavir, in addition to that he was started on hydroxyurea due to high WBC count, despite that his oxygen requirement was increasing chest X-ray showed bilateral infiltrate as illustrated in (image1), on third day of admission patient was tachypneic and desaturating on 15 liters of oxygen via non rebreathing mask so he was intubated and admitted to the intensive care unit and he was started on methylprednisolone with piperacillin/tazobactam and post intubation $\mathrm{X}$ ray chest is shown in (Image2) which worsening of the bilateral infiltrate, with endotracheal tube(white arrow), central line (yellow arrow) and NG tube (black arrow). And on the following 3 days he received 2 doses of tocilizumab, few days later the patient condition started to improve, and he was extubated on day 9 , after that his condition continued to improve during the subsequent days and he was started on imatinib as upfront.

\section{Discussion:}

Chronic myeloid leukemia (CML) is a myeloproliferative neoplasm characterized by the dysregulated production of mature and maturing granulocytes with normal differentiation, and it is associated with the fusion of two genes: $B C R$ (on chromosome 22) and $A B L 1$ (on chromosome 9) resulting in the $B C R$ - $A B L 1$ fusion gene. That gives rise to an abnormal chromosome 22 called the Philadelphia $(\mathrm{Ph})$ chromosome. CML has three phases which included; chronic phase, accelerated phase and blast phase [4].

It is well known in the literature some viral infections increases the risk of some hematological malignancy Epstein-Barr virus the risk of Burkitt lymphoma, and non-Hodgkin's lymphoma and human T-lymphotrophic virus (HTLV-1) which increase the risk of adult T-cell leukemia/lymphoma[5] but so far the exact mechanism of cancer development after viral infection is not well understood. Up to our knowledge there is no viral infection was proven to increases risk of CML.

Since the discovery of COVID 19 it has been reported in the literate to be associated with other diseases at time of presentation like association with acute ST elevation myocardial infarction[6], and the association with neurological diseases like meningitis and encephalitis [7], also it was reported with Guillain-Barré 
Syndrome[8].In Our case the presentation of COVID 19 was associated with CML at the time of presentation and up to our knowledge this is the first of such association; however this association could be only a coincidence.

\section{Conclusion:}

Although the association between CML and COVID19 in our case could be only a coincidence we reported this case in order to to pay attention for similar association which links SARS-CoV-2 and CML or other neoplasms which could be a lead for further research to understand the causality and pathophysiology for this association.

\section{Authors Contributions:}

Khaldun Obeidat: writing and editing the manuscript, clinical management

Mohamed A Yassin: Writing and editing, clinical management

Mohamed aboukamar: clinical management

\section{References:}

1. "Coronavirus disease 2019 (COVID-19)-Symptoms and causes". Mayo Clinic . Retrieved 14 April 2020.

2. A pneumonia outbreak associated with a new coronavirus of probable bat origin. Zhou P, Yang XL, Wang XG, Hu B, Zhang L, Zhang W, Si HR, Zhu Y, Li B, Huang CL, Chen HD, Chen J, Luo Y, Guo H, Jiang RD, Liu MQ, Chen Y, Shen XR, Wang X, Zheng XS, Zhao K, Chen QJ, Deng F, Liu LL, Yan B, Zhan FX, Wang YY, Xiao GF, Shi ZL

3. https://coronavirus.jhu.edu/map.html

4. Turkina, A., Wang, J., Mathews, V., Saydam, G., Jung, C.W., Al Hashmi, H.H., Yassin, M., Le Clanche, S., Miljkovic, D., Slader, C. and Hughes, T.P. (2020), TARGET: a survey of real-world management of chronic myeloid leukaemia across 33 countries. Br J Haematol. doi:10.1111/bjh.16599

5. https://www.cancer.org/cancer/cancer-causes/infectious-agents/infections-that-can-lead-tocancer/viruses.html

6. Corona Virus Disease 2019 (COVID-19) Presenting as Acute ST Elevation Myocardial Infarction. Siddamreddy $\mathrm{S}^{1}$, Thotakura $\mathrm{R}^{2}$, Dandu $\mathrm{V}^{3}$, Kanuru $\mathrm{S}^{4,5}$, Meegada $\mathrm{S}^{6}$.

7. A first case of meningitis/encephalitis associated with SARS-Coronavirus-2. Moriguchi $\mathrm{T}^{1}, \mathrm{Harii}^{2}$, Goto $\mathrm{J}^{3}$, Harada $\mathrm{D}^{3}$, Sugawara $\mathrm{H}^{3}$, Takamino $\mathrm{J}^{3}$, Ueno $\mathrm{M}^{3}$, Sakata $\mathrm{H}^{3}$, Kondo $\mathrm{K}^{3}$, Myose $\mathrm{N}^{3}$, Nakao $\mathrm{A}^{4}$, Takeda $\mathrm{M}^{5}$, Haro $\mathrm{H}^{6}$, Inoue $\mathrm{O}^{7}$, Suzuki-Inoue $\mathrm{K}^{8}$, Kubokawa $\mathrm{K}^{9}$, Ogihara $\mathrm{S}^{10}$, Sasaki $\mathrm{T}^{8}$, Kinouchi $\mathrm{H}^{11}$, Kojin $\mathrm{H}^{12}$, Ito $\mathrm{M}^{12}$, Onishi $\mathrm{H}^{13}$, Shimizu $\mathrm{T}^{13}$, Sasaki $\mathrm{Y}^{13}$, Enomoto $\mathrm{N}^{14}$, Ishihara $\mathrm{H}^{15}$, Furuya $\mathrm{S}^{12}$, Yamamoto $\mathrm{T}^{12}$, Shimada $\mathrm{S}^{16}$.

8. Guillain-Barre Syndrome associated with SARS-CoV-2 infection. Virani $\mathrm{A}^{1}$, Rabold $\mathrm{E}^{1}$, Hanson $\mathrm{T}^{2}$, Haag $\mathrm{A}^{2}$, Elrufay $\mathrm{R}^{3}$, Cheema $\mathrm{T}^{1}$, Balaan $\mathrm{M}^{1}$, Bhanot $\mathrm{N}^{3}$. 


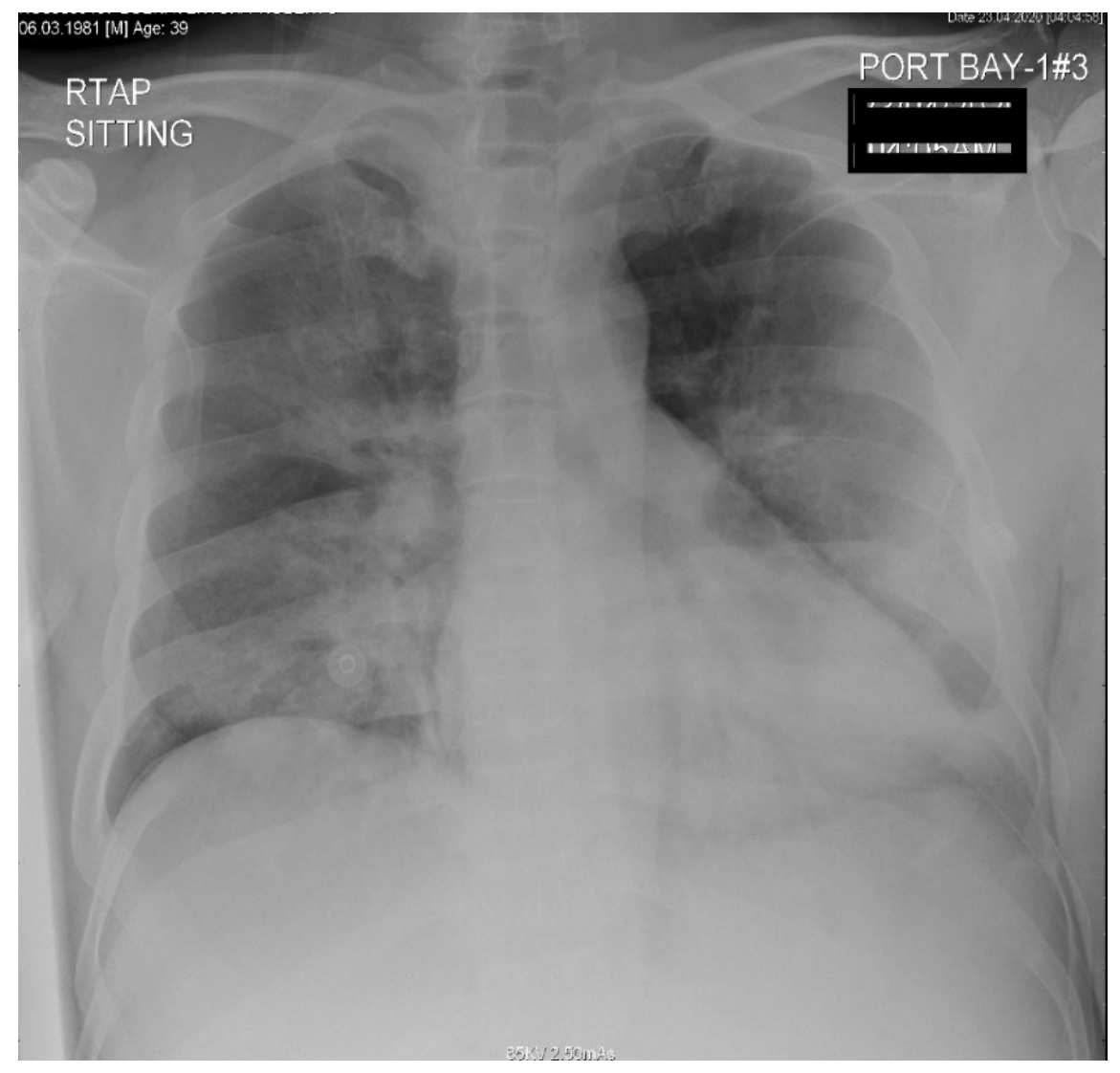




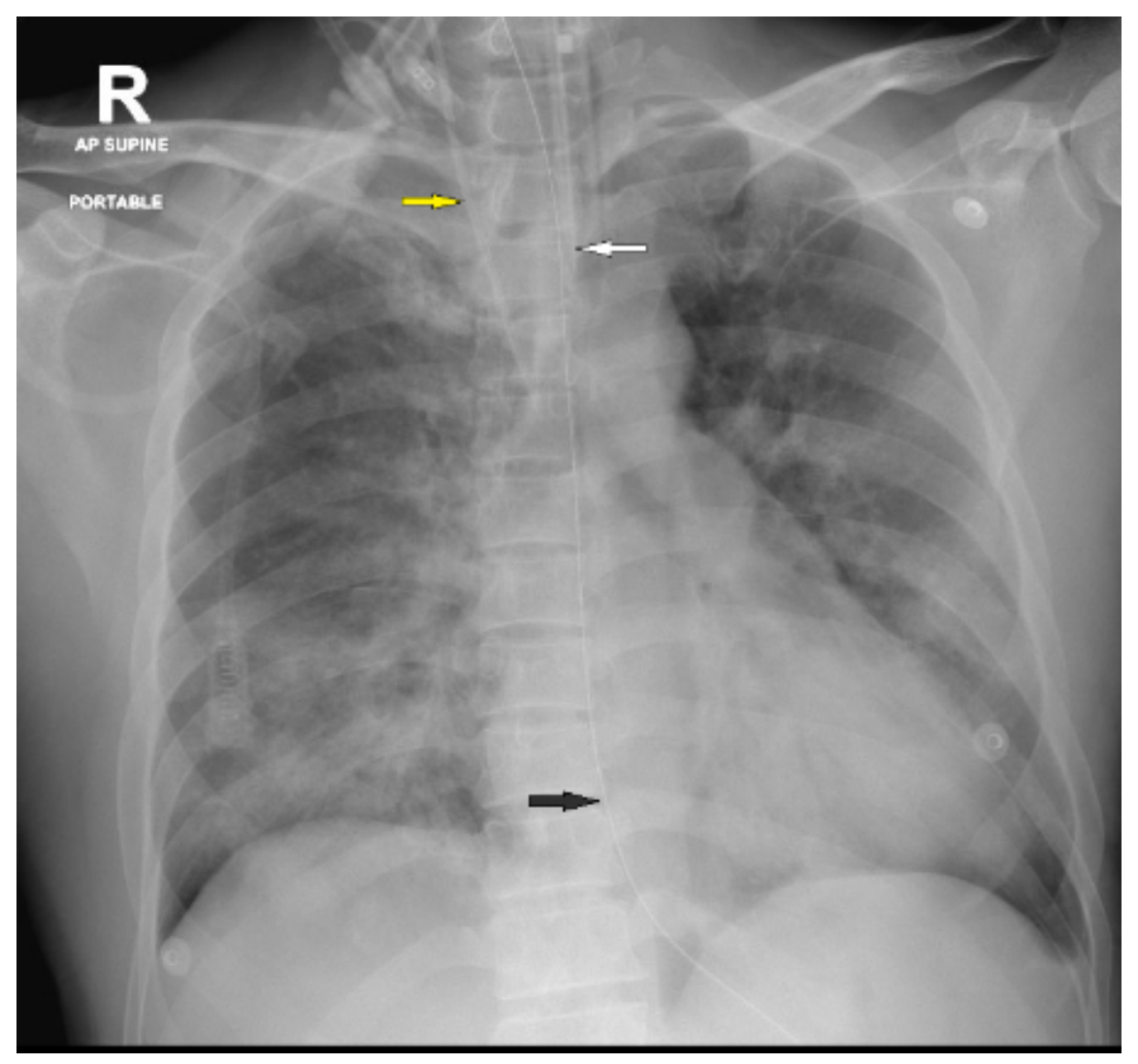

